\title{
Análisis comparativo entre las cadenas productivas del sector textil-confecciones de la provincia de Jiangsu-China y el departamento del Atlántico-Colombia
}

\section{Comparative analysis between the chain of textile-apparelin of Jiangsu Province in China and the department of the Atlantico-Colombia}

\author{
Hugo José Mercado Cervera ${ }^{1}$ Tomás José Fontalvo Herrera ${ }^{2}$ \\ Efraín de la Hoz Granadillo
}

Recibido 9 de mayo de 2011, aceptado 27 de octubre de 2011

Received: May 9, 2011 Accepted: October 27, 2011

\begin{abstract}
RESUMEN
En este artículo de investigación se presentan los resultados referentes al análisis comparativo de las cadenas productivas del sector textil-confecciones de la provincia de Jiangsu-China y el departamento del Atlántico-Colombia, identificando inicialmente las diferentes variables y categorías asociadas con las cadenas productivas, seguido de un análisis comparativo utilizando modelos de distritos industriales, modelos clúster y redes empresariales, lo que finalmente permitió establecer las diferencias de producción existentes entre las cadenas productivas del sector textil-confecciones del departamento del Atlántico y el de la provincia de Jiangsu en la República China, dos regiones que, aunque disímiles en muchos aspectos, muestran algunos puntos parecidos en materia de desarrollo de textiles y confecciones, particularmente en lo que tiene que ver con infraestructura operativa y formación de recurso humano. La evaluación de estas diferencias permitió establecer estrategias y lineamientos que pueden generar efectos positivos vía el mejoramiento de la competitividad y establecer mejores estrategias para la competencia.
\end{abstract}

Palabras clave: Cadena productiva, distritos industriales, modelo clúster, redes empresariales, competencia.

\begin{abstract}
In this research paper presents the results concerning the comparative analysis of the textile production chain-garment of Jiangsu Province, China and the Department of Atlántico, Colombia, initially identifying the different variables and categories associated with the production chains followed by a comparative analysis using models of industrial districts, cluster models and enterprise networks, which eventually led to establishing the differences in production between production chains in the textile-clothing sector of the Atlantic Department and Jiangsu Province in the Republic China, two regions that, although dissimilar in many respects, displays some similarities in the development of textiles and garments, particularly as it has to do with operational infrastructure and human resource training. The assessment of these differences allowed us to establish strategies and guidelines that can generate positive effects through improved competitiveness and ensure better for competition.
\end{abstract}

Keywords: Chain, industrial districts, cluster model, enterprise networks, competition.

1 Universidad del Magdalena. Carrera $32 \mathrm{~N}^{\circ}$ 22- 08. Santa Marta, Colombia. E-mail: hmercado@ unimagdalena.edu.co

2 Universidad de Cartagena. Avenida El Consulado Calle $30 \mathrm{~N}^{\circ}$ 48-152. Cartagena 1382. Cartagena de Indias, Colombia. E-mail: tfontalvoh@unicartagena.edu.co; edelahozg@unicartagena.edu.co 


\section{INTRODUCCIÓN}

En este artículo se presentan los resultados de la investigación realizada en las cadenas productivas del sector textil-confecciones en el que se conceptualiza y se hace un análisis comparativo entre las cadenas productivas de la provincia de Jiangsu y el departamento del Atlántico con el fin de elaborar y diseñar modelos de desarrollo para este sector industrial.

El Departamento Administrativo de Ciencia, Tecnología e Innovación-Colciencias, mediante misión tecnológica a la República China en julio del año 2006, brindó la oportunidad a un grupo de empresarios del sector textil-confección reconocidos de la Región Caribe, a funcionarios de la Gobernación del Atlántico, de los gremios como Cámara de Comercio de Barranquilla, la Asociación Colombiana de Pequeños Industriales (ACOPI) y a representantes del sector académico para que buscaran un acercamiento directo con empresas e instituciones de ese país, con el ánimo de obtener capacitación y transferencia de tecnología a través de universidades, centros tecnológicos, el gobierno, y agremiaciones de la producción en el campo textil y de confecciones, entre otros agentes. Todo esto para conocer el esquema o modelo que ha hecho que la industria china se haya posicionado a nivel mundial en los últimos años. Las empresas de confecciones chinas son hábiles a la hora de desarrollar nuevos productos y procesos debido a la cultura empresarial implementada por los nuevos inversionistas privados y a la gran disposición del gobierno para apoyarla.

Si se analizan, en el informe de resultados de la misión, las fortalezas y debilidades que presenta Colombia, en especial el departamento del Atlántico frente a China, en materia textil y confecciones, se puede manifestar que el país asiático posee ventajas en cuanto a volumen de negocios, mayor número de incentivos para el desarrollo de las industrias, la relación que existe entre las universidades, empresas y gobierno, mano de obra capacitada con acompañamiento dirigido en cada negocio, y en el manejo de información oportuna y de indicadores para la toma de decisiones acertadas. Esto sin tener en cuenta que en China existe una fuerte disciplina por el trabajo, se respeta la jerarquía, hay eficiencia administrativa, transparencia y mayor voluntad del Estado para acompañar al desarrollo de las empresas. Adicionalmente, cuentan con importante infraestructura representada en zonas económicas especiales, zonas francas, desarrollo de infraestructura vial, portuaria, comunicaciones y de servicios públicos, y seguridad jurídica para la atracción de inversiones externas.

Todas estas condiciones hacen que la provincia de Jiangsu (República de China) sea un buen referente comparativo de las cadenas productivas del sector textil-confecciones para el departamento del Atlántico (Colombia).

Con el despliegue que actualmente presenta la cadena textil-confección en la región Caribe Colombiana, la participación de diseñadores y empresarios en eventos de talla internacional, la eventual entrada del tratado de libre comercio TLC entre Colombia y Estados Unidos, traerán consigo una gran competencia con productos altamente competitivos a bajos precios y de muy buena calidad, por lo que las empresas deberán prepararse con estrategias que les permitan permanecer en el mercado, con rentabilidades razonables.

\section{MARCO TEÓRICO}

Para el establecimiento de las variables a evaluar de las cadenas productivas del sector textil se tuvieron en cuenta referentes teóricos sobre distritos industriales, clúster, redes empresariales, cadenas productivas, análisis de competencia, competitividad y factores importantes del sector textil confección.

\section{Cadena productiva}

El concepto de cadena productiva involucra un número de etapas interconectadas, a través de la unión entre producción, transformación y consumo. Esta dimensión implica que se consideren los distintos procesos productivos y relaciones económicas que se producen entre la oferta inicial y la demanda final [1].

Las cadenas pueden ser completas, integradas o incompletas.

- Una cadena productiva es completa: Si todos los componentes y eslabones están interactuando: proveedores de insumos, sistemas productivos, agroindustria, comercialización mayorista y minorista, y consumidores finales. 
- Una cadena está integrada: Si el producto cadena productiva se constituye en insumo para otra cadena.

- Una cadena productiva es incompleta cuando solo uno o unos de los componentes o etapas de la cadena productiva están identificados, pero no están eslabonados, ni cubren todos los componentes.

\section{Análisis de la competencia}

En el análisis de competitividad se identifican cinco fuerzas competitivas que son: entrada, riesgo de sustitución, poder de negociación de los compradores, poder de negociación de los proveedores y rivalidad entre los competidores actuales [2]. Se observa claramente que la competencia en un sector industrial no se limita en absoluto sólo al manejo propio de la empresa; es fundamental su entorno, como son los clientes, los proveedores, los participantes potenciales y los sustitutos. En un sentido más amplio, la competencia es una rivalidad ampliada o extensa.

En un mundo en constante cambio e interacción, cada vez más competitivo, es indispensable el conocimiento y reconocimiento, actualizado y permanente, de los mercados, visualizando no sólo la situación actual sino posibles condiciones futuras previsibles. Este conocimiento permite establecer escenarios de oferta de productos y servicios que atiendan las expectativas de los clientes, posibilitando construir y mantener posiciones ventajosas frente a los competidores.

\section{Competitividad}

La competitividad es la capacidad de una empresa u organización de cualquier tipo para desarrollar y mantener sistemáticamente unas ventajas comparativas que le permitan disfrutar y sostener una posición destacada en el entorno socioeconómico en que actúa [3].

\section{Ventajas comparativas}

Se define como la habilidad, recurso, conocimiento, atributo, etc., del que dispone una empresa y del que carecen sus competidores, y que hace posible la obtención de unos rendimientos superiores a los de estos [3]. Provienen de factores productivos existentes en un territorio, o heredados, que dan a los actores cierta superioridad frente a otros productores de ciertos bienes para determinados mercados.

\section{Ventajas competitivas}

Hace referencia a los atributos que desarrolla y forja la organización de manera consciente y por sus propios medios para mejorar su posicionamiento económico y social dentro de su área de influencia. Las ventajas competitivas suelen adquirirse mejorando los costos laborales, la productividad, la innovación, la cualificación de los trabajadores, la especialización productiva, el apoyo público y la notoriedad en el exterior. Generalmente, el desarrollo de ventajas competitivas requiere la formulación de una estrategia previa.

Las ventajas competitivas se construyen a través de los actores e instituciones de un sistema empresarial o territorio. Se relacionan más con factores como conocimiento, diseño, diferenciación del producto, eficiencias, tecnologías, emprendimiento y saber hacer. Regularmente son más difíciles de copiar por parte de la competencia y, por lo tanto, su despliegue y profundización son claves para alcanzar posicionamientos estratégicos competitivos no imitables y sostenibles [4].

\section{Modelo de clúster}

La traducción literal de la palabra "clúster", es "grupo" o "racimo", son agrupamientos de industrias productoras, de apoyo y vinculadas que se entrelazan a través de los clientes, proveedores y otras relaciones, que trabajan para apoyar, innovar y mejorar la calidad de un producto o servicio. En cada agrupamiento hay un elemento de afinidad (un producto o servicio) y tiene como objetivo fundamental mejorar la competitividad del sector como un todo, para lograrlo reúne a los diferentes actores: productores, proveedores, clientes, innovadores, intermediarios, actividades de apoyo para compartir experiencias, conocimiento, ideas, etc.

\section{Modelo del Diamante de Porter}

Plantea que la competitividad de una empresa o grupo de empresas está determinada por cuatro atributos fundamentales de su base local. Estos cuatro atributos y la interacción entre ellos explican por qué innovan y se mantienen competitivas las compañías que se ubican en regiones determinadas. En la Figura 1 se presentan gráficamente los atributos o elementos que hacen parte del modelo del diamante de Porter. 


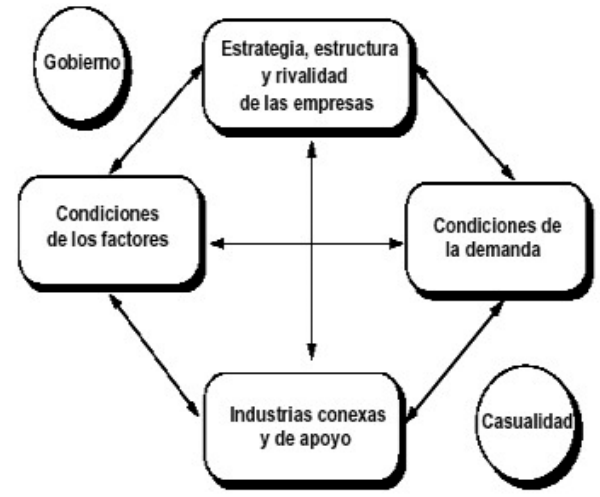

Figura 1. Modelo del Diamante de Porter. Fuente: Michael E. Porter. "La ventaja competitiva de las naciones".

\section{Modelo de distritos industriales}

Es una estructura que surge cuando un clúster desarrolla algo más que especialización y división del trabajo entre las firmas que lo integran; en un distrito industrial se presentan aspectos de eficiencia colectiva derivados de la cooperación ínter firmas, aprendizaje conjunto e innovación colectiva, adicionalmente dentro de un distrito industrial se presentan la emergencia de formas explícitas e implícitas de colaboración entre los agentes locales y las firmas de los distritos para generar la producción local y algunas veces la capacidad de innovación; asimismo se presenta la emergencia de fuertes asociaciones sectoriales [5].

Los distritos industriales se definen también como una aglomeración de cientos y a veces miles de empresas de tamaño pequeño y/o mediano orientadas al mismo sector industrial y concentradas en la misma área. Típicamente, se incluyen dentro del distrito varias etapas del proceso productivo así como servicios a los productores [6]. Los distritos industriales pueden ser descritos como sistemas productivos geográficamente delimitados [7], caracterizados por un número elevado de empresas $\mathrm{y}$ de unidades productivas de pequeña y mediana dimensión focalizadas mayoritariamente en un número reducido de fases y un mismo ciclo de producción [8].

La ventaja fundamental de los distritos reside en la capacidad que han exhibido para desarrollar un sistema común y homogéneo de valores, en el cual se reconocen todos los sujetos, y que ve en la ética del trabajo y de la actividad, en la recíproca solidaridad, en la predisposición al cambio y en el profundo respeto por la comunidad, por la familia y sus elementos caracterizadores; precisamente, esta fuerte identidad social ha permitido dos elementos de ventaja competitiva, la comunicación y la organización:

Otro rasgo de ventaja competitiva en los distritos industriales es consecuencia de su característico sistema de organización de la producción, que permite que las pequeñas empresas presenten niveles óptimos de escala en su especialización productiva, manteniendo, desde el punto de vista del distrito industrial, un nivel de activación cercano al óptimo productivo [9].

Las pequeñas empresas de los distritos industriales han seguido históricamente la estrategia de crecimiento externo con carácter general [10]. Esto, normalmente, se ha realizado o a través de la implicación, por parte de una "empresa guía", de terceras empresas autónomas en la realización de un mismo proyecto (constelaciones de empresas); o vía filiación y adquisición de nuevas unidades jurídicamente separadas gradualmente de la casa madre, que han alcanzado ciertos umbrales de dimensión (grupos de empresa). Por lo tanto, en ambos casos, el diseño estratégico puede ser calificado como crecimiento externo, ya que se basa en la utilización, aunque con modalidades diversas, de terceras empresas. No obstante, mientras en el primer caso las modalidades de crecimiento son externas, en la acepción tradicional del término, al contrario, los procesos de filiación y adquisición que definen el segundo caso (grupos de empresas) muestran una estructura productiva caracterizada por una propiedad única: se puede entonces hablar de un crecimiento externo con modalidades típicamente internas [10].

\section{Modelo de redes empresariales}

El término red significa: grupo de empresas que colaboran en un proyecto de desarrollo conjunto, complementándose unas con otras y especializándose con el propósito de resolver problemas comunes, lograr eficiencia colectiva y conquistar mercados a los que no pueden acceder de manera individual [11].

Teniendo en cuenta lo anterior, una red empresarial es una alianza estratégica entre un grupo limitado 
y claramente definido de empresas independientes, que colaboran para alcanzar objetivos comunes de mediano y largo plazo, orientados hacia el desarrollo de la competitividad de los distintos participantes [11].

Dicha definición está compuesta por los siguientes elementos funcionales:

- Es un mecanismo de cooperación entre empresas.

- Cada participante mantiene independencia jurídica y autonomía gerencial.

- Es de afiliación voluntaria.

- El objetivo es obtener beneficios individuales mediante la acción conjunta.

Por otra parte, las redes de empresas se diferencian de los clusters y los distritos industriales por las siguientes razones:

- Las redes de empresas están generalmente constituidas por un número mucho más limitado de firmas que los distritos industriales.

- Las empresas que componen una red son claramente identificables y la composición de la misma tiende a ser menos variable.

- Los miembros de una misma red no pertenecen necesariamente al mismo territorio [6].

Asimismo, los distritos industriales y redes empresariales se consideran como dos fenómenos complementarios, no jerárquicamente subordinados [12].

\section{Redes horizontales}

El Programa de las Naciones Unidas para el desarrollo (PNUD) define una red horizontal como una modalidad de cooperación entre empresas independientes, de tamaño comparable, que producen un mismo tipo de bien y deciden agruparse para comercializarlo, adquirir insumos en conjunto, coinvertir o dotarse de servicios comunes; o por empresas que se organizan para producir en conjunto un único producto, especializándose cada una de ellas en las distintas partes y componentes del mismo. En general estas redes están orientadas principalmente a la búsqueda de economías de escala y de mayor poder de negociación y suelen estar compuestas por grupos de micro, pequeñas y medianas empresas de la misma localidad y del mismo sector.

\section{Redes verticales}

El PNUD define una red vertical como aquellas modalidades de cooperación entre empresas que se sitúan en posiciones distintas y consecutivas en la cadena productiva y se asocian para alcanzar ventajas competitivas que no podrían obtener de forma individual".

\section{MARCO CONTEXTUAL}

\section{Estructura de la cadena textil y confecciones}

La cadena productiva textil-confección tiene como característica la obtención y transformación de tres insumos básicos: algodón, lana y fibras sintéticas; cubre desde la producción de hilados y telas, hasta la confección de prendas de vestir elaboradas a partir de tejidos de punto y planos.

Según la Clasificación Industrial Internacional Uniforme (CIIU), la cadena textil-confecciones comprende los rubros hilados y tejidos textiles, artículos confeccionados de materiales textiles excepto prendas de vestir, tejidos y prendas de vestir de punto, tapices y alfombras, productos de cordería, tejidos y manufacturas de algodón y sus mezclas, tejidos y manufacturas de lana y sus mezclas, tejidos y manufacturas de fibras artificiales y sintéticas y textiles no clasificados en otros rubros [13].

El perfil que muestra la cadena textil-confección, es el de un escenario muy delicado, debido a que las principales importaciones se presentan en los eslabones iniciales de la cadena, como fibra, hilados y telas; y las mayores exportaciones en el eslabón final, las confecciones, apalancando su crecimiento mediante las importaciones y compitiendo con las confecciones del exterior. En la Figura 2 se ilustran los eslabones de la cadena textil-confecciones.

En la Figura 2, el primer nivel de la cadena lo representa el sector primario, donde se cultiva el algodón, se desmota y se embala para su comercialización. Posteriormente es procesado en las hiladoras para convertirlo en hilos, con características técnicas que dependen de su posterior uso. Estas empresas de hilatura son los proveedores de las fábricas textiles, quienes convierten los hilos en telas de diferentes estilos y colores.

Las empresas de confecciones son las encargadas de transformar las telas en prendas de vestir para los 


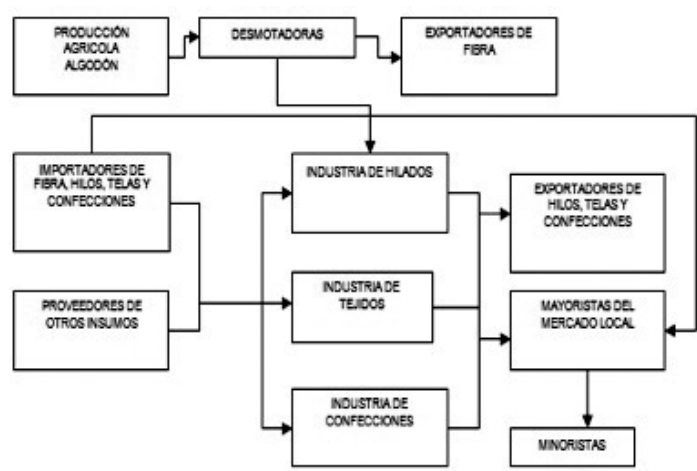

Figura 2. Cadena textil-confección.

Fuente: Resultado de la investigación.

diferentes mercados del mundo; adicionalmente se ilustra los insumos provenientes de las importaciones de materias primas de fibra, hilos, telas y confecciones, así como la interacción de las industrias mencionadas en sus procesos, productos, mercados nacionales e internacionales, para terminar en el cliente final.

\section{Estructura del sector textil y confecciones del departamento del Atlántico}

En el departamento del Atlántico no existe una cadena de textiles y confecciones como tal; en esta sección del país desde hace muchos años vienen operando varias empresas que producen cierres de cremalleras, pretinas y cintas, entre otros bienes, y una gama importante de distribuidores y minoristas de productos necesarios para la fabricación de prendas de vestir. Esta industria se encuentra localizada en su mayoría en Barranquilla, contribuyendo al desarrollo productivo de la ciudad, generando un importante aporte al crecimiento económico, a las exportaciones y al empleo.

Barranquilla siempre ha sido una ciudad pionera en la confección y la moda, muestra de ello fueron las empresas textileras que se abrieron paso gracias a ser zona portuaria. Ese sitial se perdió por un tiempo pero nuevamente ha vuelto a retomarlo gracias a la aparición de diseñadoras que le han dado mayor empuje y realce a la actividad [14].

Una de las ventajas que tiene el sector de la confección del Atlántico es su localización geográfica estratégica, la cual permite obtener a bajos costos insumos importados para la transformación y la posterior exportación de los productos finales. A ello se agrega el hecho de que la oferta de mano de obra, además de ser abundante y competitiva, se caracteriza por su alto nivel de habilidad, lo que ayuda a reducir el tiempo en la curva de aprendizaje frente a otras regiones del país.

El Atlántico posee una importante plataforma internacional de servicios que facilita la actividad de comercio exterior a los confeccionistas y al resto de empresarios. Esta actividad participa con un $15 \%$ del total de empleos industriales. El primero es el de alimentos con un $21 \%$. La participación de textiles y confecciones en el contexto nacional en términos de producción es del $4 \%$. Se estima que en el Departamento hay alrededor de 1.000 a 1.200 unidades productivas [14].

Es de comentar que las inversiones en el sector se encuentran, en su mayoría, en los subsectores dedicados a la fabricación de los tejidos planos y a los hilados de algodón, los cuales representan, según fuentes del DANE, más del 50\% de la inversión total en cada año.

\section{Estructura de la cadena productiva en la provincia de Jiangsu}

Para hacer un análisis comparativo entre el departamento del Atlántico y la provincia de Jiangsu, es necesario entender un poco el milagro chino de los últimos tiempos. El crecimiento del producto interno bruto de la República Popular China del año 2004 fue del orden del 9,5\%, sus exportaciones aumentaron en un $35 \%$ y su demanda de petróleo alcanzó niveles de los 6,4 millones de barriles diarios, superando en un millón el consumo del Japón. Sus exportaciones de mercancía alcanzaron la cifra de 593.400 millones de dólares convirtiéndose en el socio comercial más importante del Japón, por delante de los Estados Unidos. Es el responsable del $30 \%$ del consumo mundial de productos como el carbón, acero, algodón y el arroz; además es el primer productor mundial de productos textiles, juguetes, calzado, artículos electrónicos como televisores, reproductores de DVD, teléfonos móviles, etc. Y adentrándose con éxito en sectores como de computadores y la biotecnología [15].

Las razones del fuerte crecimiento desde finales de los años setenta son diversas, pero entre ellas destacan las siguientes: unas buenas condiciones de partida al iniciar la reforma, una privilegiada situación geográfica y una estrategia de transición 
desde la planificación central particularmente exitosa. Además, China se ha convertido en un gran receptor de inversión directa extranjera, aproximadamente unos 53.500 millones de dólares en el 2003 y 60.630 millones en el 2004, culminando una trayectoria ascendente que contrasta con los vaivenes de la inversión extranjera en América Latina. Desde el 2003 China es el primer receptor mundial de inversión directa extranjera.

En textiles y artículos de confección, China efectuaba en 1990, el 8\% de las exportaciones mundiales, proporción que aumentó en 2003 al 20\%. En la actualidad, al finalizar diferentes acuerdos sobre Textiles y Vestuario establecido, la cuota podría aumentar al 50\% o incluso más.

China dispone de una mano de obra abundante, dadas las amplias reservas que existen en el campo donde viven cerca de 800 millones de personas, bien formada y que trabaja por salarios que son todavía muy bajos; en efecto, mientras el salario actual en China es 0.44 dólares la hora, en Colombia y en Latinoamérica el promedio es de 2 dólares. Además, la mano de obra es fiable, por su elevado grado de disciplina.

Jiangsu, es una provincia costera, sobre el mar amarillo, bañada por el río Yangzi con algo más de 100.000 kilómetros cuadrados. Su población aproximada es de 70 millones de habitantes de mayoría etnia Han. Limita al norte con la provincia de Shandong, con Anhui y con Zhejiang al oeste. Su localización y proximidad a la ciudad de Shanghai la hacen sumamente atractiva y próspera. Entre sus principales industrias se encuentran las alimenticias, las químicas y las de textiles. Estas características geográficas y topográficas la hacen muy parecidas a las condiciones que posee el departamento del Atlántico, de allí que se reconozca a esta provincia como hermana del departamento del Atlántico.

La provincia de Jiangsu posee bases industriales para el desarrollo de la cadena textil- confecciones, ubicadas en las ciudades de Taicang, Tongzhou, Changshu, Jiangyin, Zhangjiagang y Dongguan. Donde 627.000 trabajadores laboran en aproximadamente 12.000 empresas, en la fabricación de hilos a base de algodón, lana, tejidos de punto, ropa, fibras químicas y los acabados, así como maquinaria para uso textil. Produce cerca del 35\% de los ingresos de la provincia, el $22 \%$ del total de las exportaciones y el $30 \%$ de los activos totales.

\section{METODOLOGÍA}

La investigación realizada es de tipo aplicada, descriptiva debido a que pretende la utilización de los conocimientos y experiencias adquiridos sobre centros de desarrollo productivos, para el desarrollo de un ente que articule mediante mecanismos sistémicos la prestación de los servicios a micros, pequeñas y medianas empresas del sector textilconfecciones. Se utilizó la observación, la entrevista y la encuesta como técnicas de recolección de información para determinar las características del sector textil-confecciones, la metodología utilizada corresponde a los métodos inductivo-deductivo y el método de análisis y síntesis.

Para la realización del trabajo de campo en primera instancia se delimitó a las pequeñas y medianas empresas de confecciones del sector textil-confecciones del departamento del Atlántico, conformado por 38 empresas según la base de datos obtenida de la Cámara de Comercio de Barranquilla. La metodología se orienta a determinar el indicador más apropiado que servirá para medir la productividad de ambas regiones. Para este caso y dadas las limitaciones que se encontraron en materia de información tanto en el Atlántico como Jiangsu, se tomó el índice de productividad laboral, debido al alto nivel de contenido manual de sus procesos productivos. Una vez seleccionado el indicador, se efectúan los cálculos para conocer la situación que presenta cada una de estas zonas geográficas. Para colocar las regiones en igualdad de condiciones se realiza un análisis estructural de la cadena productiva, donde sólo se tienen en cuenta aquellos eslabones comunes, mediante la escogencia de las variables más importantes para el estudio.

Los factores analizados fueron: Tecnología, sistemas de información, recursos humanos y organización. Posteriormente se realiza una evaluación de los resultados arrojados, lo cual permite conocer la situación real sector textil-confecciones del Departamento, frente a la provincia de Jiangsu. La Figura 3 ilustra la metodología para el análisis comparativo 


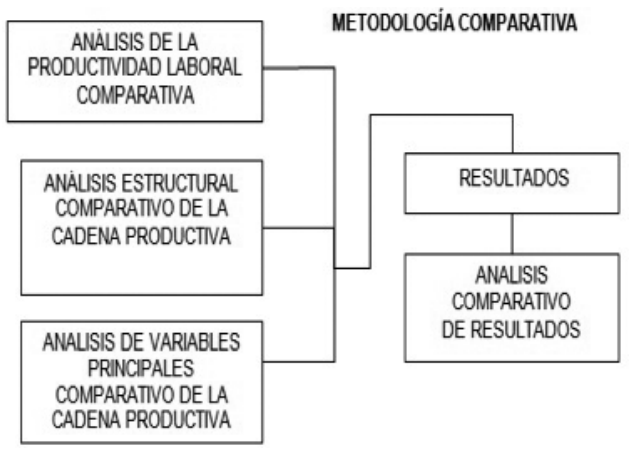

Figura 3. Metodología análisis comparativo. Fuente: Resultado de la investigación.

\section{Definición de variables operacionales}

Para la definición de las variables operacionales se utilizó la técnica de juicio de expertos con la que se identificaron las variables o aquellos factores con mayor incidencia en la productividad de un sector económico. Para esto se entrevistaron empresarios expertos del sector textil-confecciones del departamento del Atlántico, que hicieron parte de la misión tecnológica realizada a la República China y en especial a la provincia de Jiangsu. En la selección de las variables, se tuvieron en cuenta aquellas que permiten medir o cuantificar lo relacionado con los factores macro mencionados, es decir, llevarlas a un nivel operativo con lo cual se puedan analizar e identificar las diferencias que presentan desde la perspectiva del desarrollo productivo de las empresas. A continuación se definen las variables operacionales que se consensaron en cada uno de los factores de la investigación.

\section{Tecnología}

- Inversión: El nivel de inversión representa la cantidad de recursos económicos que una empresa destina para satisfacer un plan operativo, el cual ha sido establecido previamente según necesidades o como consecuencia de su planeación táctica o estratégica.

- Maquinaria: En este ítem se evalúa el estado de la maquinaria o sea, el grado de obsolescencia, nivel de automatización, escasez de maquinaria (requerimientos vs. disponibilidad), así como las tecnologías de apoyo en las tareas operativas, tales como lectores de código de barra, equipos para el control de los estándares de calidad, entre otros.
- Factores externos: Se consideran factores externos aquellos que no son controlables directamente por la empresa, pero que impactan de manera sensible sobre los factores macro que se analizan. En el caso de la tecnología, se estudian aspectos tales como el apoyo que presta el gobierno para que estas empresas inviertan en innovación tecnológica y la falta de condiciones propicias para el desarrollo tecnológico.

\section{Sistemas de información}

- Inversión: No basta realizar inversiones en sistemas de información, sino que es necesario, además, tener la capacidad de identificar las necesidades y saber cómo engranar el sistema de datos con los procesos.

- Procesos y plataforma informática: Los sistemas de información se definen como un conjunto de componentes interrelacionados que recolectan (o recuperan), procesan, almacenan y distribuyen información para apoyar la toma de decisiones y el control de una organización [16].

La definición anterior refleja tres aspectos básicos de los sistemas de información.

1. Un sistema de información está formado por un conjunto de componentes.

2. Las actividades que realizan los sistemas de información (recolección, procesado, almacenamiento y distribución de la información).

3. Apoyar la toma de decisiones y el control de una organización.

- Factores externos: Son aquellos que no son controlables por la empresa, que influyen sobre los niveles de inversión, el desarrollo y la de los sistemas de información, así como el impacto que esto puede generar dentro de la empresa. Como por ejemplo nuevas leyes tributarias, devaluación del peso frente al dólar, nuevas tecnologías, etc.

\section{Recursos humanos}

- Nivel de formación: La formación es el grado de preparación con el que cuenta una persona, refleja el nivel de estudios y por ello representa el manejo y la magnitud de conocimientos del individuo. 
- Capacitación y desarrollo del recurso humano: El Desarrollo de Recursos Humanos (DRH) es una función importante de la administración de recursos humanos que consiste no sólo en capacitación, sino también en actividades de planeación y desarrollo de carreras individuales, desarrollo organizacional y evaluación del desempeño, una actividad que destaca las necesidades de capacitación y desarrollo (CyD). $\mathrm{La} \mathrm{CyD}$ es el centro de un esfuerzo continuo diseñado para mejorar las capacidades de los empleados y el desempeño organizacional. Algunos gerentes utilizan los términos capacitación y desarrollo indistintamente. Sin embargo, otras fuentes hacen la siguiente distinción: la capacitación imparte a los empleados los conocimientos y las habilidades necesarias para sus actividades actuales [17].

- Contratación: La contratación es el proceso organizacional y legal mediante el cual se selecciona el personal de acuerdo al perfil del cargo y se vincula a la empresa, dependiendo de la relación que se quiera establecer con los nuevos empleados.

- Rango de edades: Este se considera como uno de los requisitos y parámetros por medio de los cuales se filtra y selecciona el personal. La mayoría de las empresas colombianas en la actualidad quieren laborando en sus instalaciones gente con experiencia, menores de 30 años, flexibles a los cambios de la organización y con capacidad para adaptarse a las circunstancias.

- Género del personal: Esta variable define el interés o inclinación de las empresas a seleccionar y contratar hombres y/o mujeres para el desarrollo de sus actividades.

- Motivación: La motivación es un factor emocional básico para el ser humano y para cualquier profesional, estar motivado significa realizar las tareas cotidianas sin apatía y sin sobreesfuerzo adicional; aunque para unos el trabajo o las actividades de todo orden pueden representar una carga, para otros es un acicate, un revulsivo y a veces una liberación. Muchos seres humanos encuentran en el trabajo un refugio a sus frustraciones personales y profesionales, y se automotivan en su trabajo por ser la única forma de alcanzar la autoestima y el reconocimiento profesional y social [18].

\section{Organización}

Las empresas para poder garantizar su funcionamiento y su persistencia en el tiempo deben contar con una estructura administrativa que les permita orientar y establecer el poder para la toma de decisiones y organización de la empresa.

- Estructura Organizacional: A pesar de que existen varios tipos de estructura organizacional, para el estudio se contempla la funcional y la que se lleva a cabo por proceso.

- Sistemas de Gestión de Calidad: Un Sistema de Gestión de la Calidad es una herramienta administrativa que facilita el manejo sistémico de una organización, propiciando un cambio en la cultura organizacional de tal manera que se dé un enfoque hacia el cliente, mediante la implementación de diferentes procesos.

- Nivel de Asociatividad: Es el mecanismo de cooperación entre empresas de distintos niveles: pequeñas, medianas, micros y grandes donde cada una participa, conservando su independencia y autonomía gerencial. El objetivo principal es obtener economías de escala, penetrar a nuevos mercados y en últimas incrementar el grado de competitividad de todas las unidades económicas.

\section{RESULTADOS}

\section{Tecnología}

Como resultado del factor tecnología se encontró que las principales diferencias se presentan en el plan de inversión; los empresarios de la provincia de Jiangsu invierten más a largo plazo como consecuencia de las políticas del gobierno, que les proporciona mayor garantía y seguridad para su inversión. En contraste, las empresas del departamento del Atlántico realizan poca inversión en el largo plazo. Pero en las variables como los tipos de maquinaria y los procesos de transformación no existen grandes diferencias.

\section{Sistemas de información}

En este factor se encuentra que el plan de inversión, es a largo plazo y enfocado en el área productiva, 
a diferencia de los empresarios del Atlántico que realizan inversión en el corto plazo en áreas administrativas y de mercado. Asimismo, en los niveles de inversión y en el tipo de plataforma informática no se presentan diferencias marcadas.

\section{Recursos humanos}

En este factor se encontró que no existen grandes diferencias en los niveles de formación, los programas de capacitación, tipos de contratos laboral y rango de edades del personal de trabajadores, pero a pesar de esto los niveles de productividad laboral presentan diferencias importantes, atribuibles a la cultura laboral de los trabajadores de Jiangsu, observados en su actitud, disciplina y comportamiento en general.

\section{Organización}

Del análisis del factor Organización se encontró que las estructuras organizacionales en la provincia de Jiangsu están diseñadas para la fabricación de grandes lotes de producto, debido al tamaño del mercado chino, significativamente mayor al de Colombia, pero en la importancia de la implementación de los sistemas de gestión de calidad, no hay diferencias. En contraste, la importancia que presentan las organizaciones de la provincia de Jiangsu para adoptar sistemas de cooperación entre empresas, es una estrategia definitiva para lograr ser más competitivos.

\section{Productividad laboral comparativa}

La medición de la productividad es un ejercicio que le brinda a las empresas datos concretos para compararse con otras organizaciones, logrando información sobre estrategias, procesos y medidas que pueden ayudar a tomar decisiones para cerrar brechas o aprovechar ventajas competitivas.

En la Tabla 1 se presentan algunos datos para toda la cadena textil-confección en el año 2004 calculados por la Oficina Nacional Textil del Ministerio de Comercio de China, en las bases industriales más importantes de la provincia de Jiangsu.

La productividad laboral promedio de toda la cadena textil-confección de la provincia de Jiangsu para el año 2004 fue de US\$9.785 por cada empleado y Jiangyin es la base industrial más productiva laboralmente con un valor generado por cada empleado de US\$12.815.
Tabla 1. Productividad laboral provincia de Jiangsu (2004).

\begin{tabular}{|l|c|c|c|}
\hline $\begin{array}{c}\text { Base } \\
\text { Industrial }\end{array}$ & $\begin{array}{c}\text { Valor } \\
\text { Agregado } \\
\text { USD\$ }\end{array}$ & $\begin{array}{c}\text { Trabaja- } \\
\text { dores } \\
\text { Emplea- } \\
\text { dos }\end{array}$ & $\begin{array}{c}\text { Produc- } \\
\text { tividad } \\
\text { Laboral } \\
\text { (USD\$/ } \\
\text { Em) }\end{array}$ \\
\hline Taicang & 570.375 .000 & 54.000 & 10.563 \\
\hline Tongzhou & 1.125 .000 .000 & 105.000 & 10.714 \\
\hline Changshu & 975.000 .000 & 100.000 & 9.750 \\
\hline Jiangyin & 1.473 .750 .000 & 115.000 & 12.815 \\
\hline Zhangjiagang & 866.250 .000 & 100.000 & 8.663 \\
\hline Dongguang & 1.125 .000 .000 & 153.000 & 7.353 \\
\hline TOTAL & 6.135 .375 .000 & 627.000 & 9.758 \\
\hline
\end{tabular}

Fuente: Information Office of China National Textile.

Para el Atlántico, se observa que la productividad laboral en el sector textiles y confecciones experimentó entre el período 2001-2004 una tasa de crecimiento anual de $9 \%$, al pasar de US\$6.012 a US\$7.848 de un año a otro, notándose un incremento sostenido.

Estos resultados son el valor base de comparación para la productividad laboral de las empresas pertenecientes al sector de textiles-confecciones del departamento del Atlántico, donde aparece en el año 2004 una productividad laboral promedio de US\$ 7.848 por persona. La Tabla 2 muestra la productividad laboral del departamento del Atlántico observada entre los años 2001 al 2004 en el sector textil-confecciones.

Tabla 2. Productividad laboral departamento del Atlántico en el sector textil-confecciones.

\begin{tabular}{|l|c|c|c|}
\hline Año & $\begin{array}{c}\text { Valor } \\
\text { agregado } \\
\text { USD\$ }\end{array}$ & $\begin{array}{c}\text { Trabajadores } \\
\text { empleados }\end{array}$ & $\begin{array}{c}\text { Productividad } \\
\text { laboral } \\
\text { (USD\$/Em) }\end{array}$ \\
\hline 2001 & 31.565 .250 & 5.250 & 6.012 \\
\hline 2002 & 34.390 .045 & 5.425 & 6.339 \\
\hline 2003 & 41.278 .340 & 5.560 & 7.424 \\
\hline 2004 & 43.145 .685 & 5.498 & 7.848 \\
\hline
\end{tabular}

Fuente: Departamento Administrativo Nacional de Estadísticas. DANE, 2004.

\section{Análisis comparativo}

En el presente análisis comparativo se tuvieron en cuenta algunas consideraciones especiales: 
- Los mercados hacia los cuales se dirigen los productos de las empresas del sector textilconfecciones de la provincia de Jiangsu y las del departamento del Atlántico difieren considerablemente en volumen y en diseños.

- Los chinos consideran su economía como casi perfecta, en la medida en que los requerimientos de cantidad de producción deben estar diseñados para grandes lotes de manufactura, debido a su gran número de habitantes (1.340 millones).

- La diferenciación en los diseños en el mercado chino no es considerada importante para la mayoría de los consumidores, a pesar de que el número de personas que poseen mayor poder adquisitivo se ha incrementado de manera importante en los últimos años.

- El Gobierno apoya mediante planes estratégicos la inversión de grandes empresas (locales y extranjeras) en lugares especiales para el desarrollo de su economía. Incentivos e infraestructura adecuados para ser competitivos a nivel mundial. La provincia de Jiangsu es uno de ellos, debido a su situación geográfica incomparable, allí se encuentran localizados los mayores distritos industriales del país.

En las empresas del departamento del Atlántico estudiadas se observó que poseen algunas de las características de modelo de red empresarial. Esto corresponde a aproximaciones, que precisamente se trata de resolver, mediante la puesta en marcha de un modelo de desarrollo productivo que logre articular sus intereses colectivos.

Asimismo, se puede observar que el modelo productivo de la provincia Jiangsu se ubica más desde la dinámica de un modelo de distrito industrial.

La Tabla 3 muestra la participación porcentual en la actividad textil-confecciones en cada uno de los eslabones y el valor de la productividad laboral promedio en la provincia de Jiangsu y en el departamento del Atlántico. El valor de la productividad laboral que se tiene en cuenta para el análisis de las dos zonas geográficas indicadas es de los eslabones tejido y confección. Mientras en la provincia de Jiangsu el resultado fue de US\$ 4.012 por empleado, para el Atlántico la cifra sumó US\$ 3.044, es decir, un 24\% menor al valor de dicha provincia.

Tabla 3. Productividad laboral promedio comparativo por eslabón

\begin{tabular}{|l|c|c|c|}
\hline $\begin{array}{l}\text { Eslabón de } \\
\text { la Cadena } \\
\text { Textil } \\
\text { Confección }\end{array}$ & $\begin{array}{c}\text { Partici- } \\
\text { pación } \\
\%\end{array}$ & $\begin{array}{c}\text { Productividad } \\
\text { Laboral } \\
\text { Jiangsu por } \\
\text { eslabón } \\
\text { (USD\$/Em) }\end{array}$ & $\begin{array}{c}\text { Productividad } \\
\text { Laboral } \\
\text { Atlántico por } \\
\text { eslabón } \\
\text { (USD\$/Em) }\end{array}$ \\
\hline Algodón & 9 & 881 & 668 \\
\hline Hilados & 10 & 979 & 742 \\
\hline Tejido & 26 & 2.544 & 1.930 \\
\hline Confección & 15 & 1.468 & 1.114 \\
\hline
\end{tabular}

Fuente: Resultado de la Investigación.

\section{CONCLUSIONES}

Una de las razones que constituyó el proyecto de investigación es la necesidad de mejorar las cadenas productivas del sector textil en el departamento del Atlántico en lo referente a su competencia y competitividad, para lo cual se realizaron estudios de algunos esquemas en la perspectiva del número de empresas donde se determinó lo siguiente: distrito industrial, clúster y redes empresariales, los cuales, según la literatura económica, presentan diferencias marcadas, así: mientras el primero abarca entre cientos y miles unidades productivas, el segundo y el tercero, en este aspecto, son limitados e identificables.

Las empresas pertenecientes a un clúster o a un distrito industrial deben necesariamente localizarse cerca, ya sea en la misma área o en la misma región geográfica; mientras que esto no pasa en las redes empresariales, por cuanto no es fundamental para su operación. Los modelos de redes empresariales y distritos industriales están diseñados para cubrir las necesidades de las pequeñas y medianas empresas, lo que las hace las únicas beneficiarias de sus respectivos proyectos. Los clúster, por el contrario, integran diferentes tipos de empresas, sin importar su tamaño o localización en la cadena de valor.

En los distritos industriales, la mayoría de las empresas asociadas están especializadas y desarrollan sólo una (o en su defecto pocas) etapa del proceso productivo, mientras en los clúster como en las redes empresariales, la mayoría de las empresas 
realizan todas las fases de su proceso productivo, y hacen parte las empresas pertenecientes a diferentes eslabones de la cadena productiva.

El objetivo principal que persiguen las empresas de los distritos industriales es la eficiencia colectiva derivada de la cooperación interfirmas, aprendizaje conjunto e innovación colectiva; en los clúster se busca mejorar la competitividad del sector como un todo; y en las redes empresariales se persiguen resolver problemas comunes, especializar los procesos, lograr eficiencia del grupo, conquistar mercados y acceder a servicios que resultan inaccesibles de manera individual.

Los modelos de distritos industriales, redes empresariales y clúster tienen en común que en todos hay afiliación voluntaria, independencia jurídica y autonomía gerencial. También se observa que en los diferentes modelos existe una buena y estrecha relación con las entidades bancarias y de financiamiento, y con los proveedores de materias primas e insumos especializados.

Las empresas que actúan en los distritos son por lo general productoras de bienes finales, empresas monofase y auxiliares, que interactúan para ayudarse y complementarse unas con otras. En los clúster intervienen compañías de productos finales o de servicios, proveedores de insumos especializados, componentes, maquinaria y servicios, instituciones financieras, firmas en industrias relacionadas, instituciones de educación, centros de investigación, instituciones gubernamentales y en general, toda organización que de alguna manera influya en el desempeño del mismo. En las redes se integran directamente empresas de la misma posición y/o de posiciones consecutivas de la cadena productiva.

Del análisis de los factores estudiados se puede concluir que las organizaciones de la provincia de Jiangsu basan su desarrollo productivo y competitivo sobre la cooperación o asociatividad empresarial, apoyadas por políticas del gobierno nacional, facilitando la inversión en tecnología y sistemas de información a largo plazo con la seguridad y garantía en la inversión, situación difícilmente comparable con las políticas e incentivos existentes en el departamento del Atlántico.
La economía perfectamente competitiva del mercado chino también marca la diferencia, sobre todo en los niveles o volúmenes de producción, estableciendo como factor determinante organizaciones con economías de escala, condición que no se presenta en el mercado colombiano y en especial del departamento del Atlántico, donde predomina la diferenciación de los productos o los diseños como estrategia competitiva.

En general las variables contempladas en el factor recurso humano muestran condiciones laborales similares en las dos regiones comparadas, pese a esto, la provincia de Jiangsu presenta un mayor nivel de productividad laboral atribuible a aspectos culturales y al sistema político y socio económico del país.

De lo anterior se desprende la necesidad de desarrollar políticas gubernamentales en donde se pueda incentivar la inversión en tecnología y sistemas de información con una visión de largo plazo, sobre todo en áreas productivas de la organización, promover la asociatividad o sistemas de cooperación empresarial como una estrategia competitiva, con la participación del gobierno departamental y organizaciones académicas y gremiales y propiciar una cultura laboral basada en el liderazgo, compromiso, disciplina y el trabajo en equipo, conciliando los objetivos colectivos y los individuales para lograr una actitud positiva frente al trabajo.

\section{REFERENCIAS}

[1] M. Gottret y M. Lundy. "Gestión de Cadenas Productivas". Impresiones Sagitario, p. 165. La Paz, Bolivia. Septiembre 2007. ISBN: 978-99954-0-273-0.

[2] M. Porter. "Estrategia Competitiva". Editorial Continental. Primera Edición. DF, México, p. 389. 2002. ISBN: 978-96826-1-184-1.

[3] M. Fernández y J. Sánchez. "Eficacia Organizacional". Ediciones Díaz de Santos, p. 340. S.A. Madrid, España, 1997. ISBN: 978-84797-8-312-9.

[4] Ministerio de Comercio, Industria y Turismo. "Estructura Productiva y de Comercio Exterior del Departamento del Atlántico". 2004. URL: http://www.presidencia.gov. 
co/tlc/documentos/atlantico.pdf . Fecha de consulta: Abril 2010.

[5] J. Humphrey and H. Schmitz."Principles for Promoting Cluster and Networks of SMES". Discussion Paper $\mathrm{N}^{\circ}$ 1.Vienna, Austria. 1996.

[6] M. Dini."Enfoques Conceptuales para el Estudio de Pequeñas y Medianas Empresas, Mimeo". CEPAL. Santiago de Chile, Chile. 1997.

[7] A. Marshall. "Principles of Economics". Ediciones Abridged. p. 740. New York, EE.UU, 2009. ISBN: 978-15739-2-140-4.

[8] G. Becattini. "Dal 'Settore' Industriale al 'Distretto' Industriale. Alcune Considerazionisull' Unità di Indaginedell' Economia Industriale". Rivista di Economia e Politica Industriale, pp. 7-21. Abril 1979. ISSN: 0390-041.

[9] P. Bianchi. "Produzione e Potere di Mercato". Ediesse, p. 267. Roma, Italia, 1991. ISBN: 978-88230-0-071-1.

[10] G. Lorenzoni. "L'Architettura di Sviluppo delle Imprese Minori". Il Mulino, p. 186. Bologna, Italia. 1990. ISBN: 978-88150-2-464-0.

[11] United Nations Industrial Development Organization, The UNIDO Cluster/Network Development Program, UNIDO, Vienna, Austria, 1993.
[12] V. Olivanti. "L'impresa a Rete nei Settori Tradizionali: Potenzialità e Limiti". Economia Marche. Nún. 1. Italia. 1992.

[13] Colombia compite. On Line. Fecha de consulta: marzo 2008. URL: http://www. colombiacompite.gov.co

[14] Cámara de Comercio de Barranquilla. "Una ventana al mundo Plataforma K". Revista $\mathrm{N}^{\circ} 25.2009$. Fecha de consulta: abril 2011. URL: http://www.camarabaq.org.co/images/ pdf/la_revista/revista25_2009.pdf

[15] P. Bustelo. "Cuaderno de Información Económica". Real Instituto Elcano de Madrid. $\mathrm{N}^{\circ}$ 186. Junio 2005.

[16] V. Fernández. "Desarrollo de Sistemas de Información. Una metodología basada en el modelado". Ediciones UPC. Barcelona, España, p. 218. 2006. ISBN: 84-8301-852-4.

[17] R. Wayne y R. Noe. "Administración de Recursos Humanos". Novena edición. Editorial Pearson Prentice Hall. México, p. 202. 2005. ISBN: 970-26-0641-1.

[18] M. Espada. "Nuestro Motor Emocional. La Motivación". Ediciones Díaz Santos, p. 190. Madrid España, 2002. ISBN: 978-84797-8-540-6. 